\title{
OBSERVATIONS OF MULTIPLY IONIZED TUNGSTEN RADIATION IN THE PLT DISCHARGES
}

\author{
BY \\ E. HINNOV \\ AND \\ M. MATTIOLI*

\section{PLASMA PHYSICS LABORATORY}

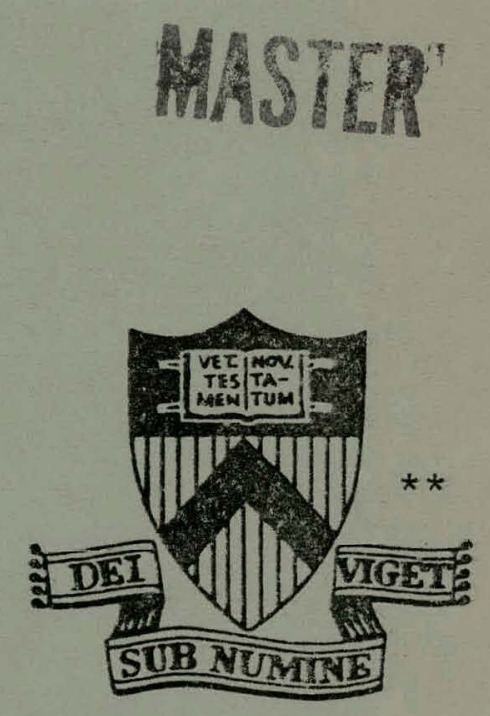

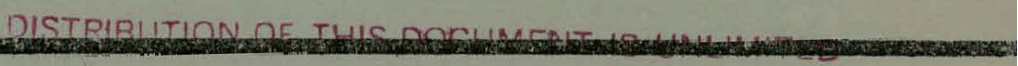

\section{PRINCETON \\ UNIVERSITY PRINCETON, NEW JERSEY}

This work was supported by U. S. Energy Research and Development Administration Contract EY-76-C-02-3073. Reproduction, translation, publication, use and disposal, in whole or in part, by or for the United States Govermment is pernitted. 


\section{DISCLAIMER}

This report was prepared as an account of work sponsored by an agency of the United States Government. Neither the United States Government nor any agency Thereof, nor any of their employees, makes any warranty, express or implied, or assumes any legal liability or responsibility for the accuracy, completeness, or usefulness of any information, apparatus, product, or process disclosed, or represents that its use would not infringe privately owned rights. Reference herein to any specific commercial product, process, or service by trade name, trademark, manufacturer, or otherwise does not necessarily constitute or imply its endorsement, recommendation, or favoring by the United States Government or any agency thereof. The views and opinions of authors expressed herein do not necessarily state or reflect those of the United States Government or any agency thereof. 


\section{DISCLAIMER}

Portions of this document may be illegible in electronic image products. Images are produced from the best available original document. 


\section{NOTICE}

This report was prepared as an account of work sponsored by the united States Govermment. Neither the United States nor the United States Energy Research and Development Administration, nor any of their employees, nor any of their contractors, subcontractors, or their employees, makes any warranty, express or implied, or assumes any legal liability or responsibility for the accuracy, completeness or usefulness of any information, apparatus, product or process disclosed, or represents that its use would not infringe privately owned rights.

Printed in the United States of America.

Available from

National Technical Information Service

U. S. Department of Commerce 5285 Port RoYal Road

Springfield, Virginia 22151

Price: Printed Copy $\$ \ldots$; Microfiche $\$ 3.00$

*Pages

$$
\begin{gathered}
1-50 \\
51-150 \\
151-325 \\
326-500 \\
501-1000
\end{gathered}
$$

NTIS

Selling Price

$\$ 4.00$

5.45

7.60

10.60

13.60 


\title{
OBSERVATIONS OF MULTIPLY IONIZED TUNGSTEN RADIATION IN THE PLT DISCHARGES
}

\author{
E. HINNOV \\ Plasma Physics Laboratory. Princeton . University \\ Princeton, New Jersey, U.S.A. \\ M. MATTIOLI \\ EURATOM/CEA A.sSOC. , \\ Fontenay-aux-Roses, France
}

\begin{abstract}
Spectral and spatial distributions of radiation bands with peaks at 33,51 and $60 \AA$, ascribed to $4 d-4 f$ transitions of tungsten ions in the range about $\mathrm{W} x \mathrm{X}-$ $\mathrm{W} X X X V$, have been measured in discharges of different electron temperatures.
\end{abstract}

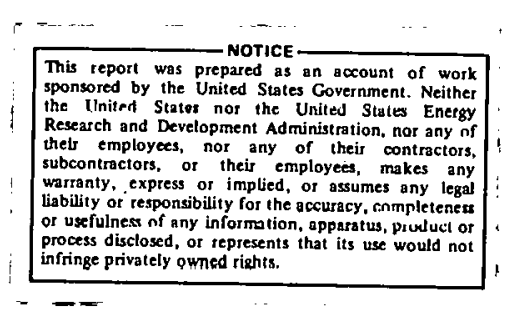

DISTRIBUTION OF THIS DOCUMENT IS UNLIMITEO 
The observations described in this paper were carried out in the PLT tokamak [1] at Princeton. The plasmas are produced by a toroidal current in a toroidal magnetic field, approximately $450 \mathrm{k}$-amps and $32 \mathrm{k}$-gauss, respectively, in the present experiments. The major radius, $R$, of the torus is $132 \mathrm{~cm}$, minor radius, a, $40 \mathrm{~cm}$. The minor radius is determined by a massive tungsten rail aperture limiter at one toroidal location. The discharge is produced in hydrogen or deuterium, but the plasma contains usually several per cent oxygen and carbon impurities (desorbed from the walls at the beginning of the discharge), of the order of $0.1 \% \mathrm{Fe}, \mathrm{Cr}$ and $\mathrm{Ni}$ ions, and so far undetermined amount of tungsten ions. A discharge typically lasts $0.5-1.0$ sec., most of which time it is in a quasisteady state, i.e., its characteristics (temperature, density, etc.) change slowly in the time scale of the energy replacement time, $\tau_{E} \equiv$ plasma energy/power input, $\left(\tau_{E} \approx 5-50 \mathrm{msec}\right.$, depending on plasma conditions). The average electron densities in the present experiments were in the range $3-5 \times 10^{13} \mathrm{~cm}^{-3}$, with the radial distributions more-or-less parabolic within the limiter radius. The electron temperature $\mathrm{T}_{\mathrm{e}}(\mathrm{r})$ usually exhibits a profile peaked in the center; with $\mathrm{T}_{\mathrm{e}}(0)$ ranging from $0.6 \mathrm{keV}$ to over $2 \mathrm{keV}$. However, often a lower-temperature discharge develops a central depression, with maxima of $0.6-0.8 \mathrm{keV}$ at $\mathrm{r} \approx 15-20 \mathrm{~cm}$ and $\mathrm{T}_{\mathrm{e}}(0)$ as $10 \mathrm{w}$ as $200-300 \mathrm{eV}$. The radial current density and power input density distribution 
is thought to follow the temperature distribution fairly closely. The consequent ohmic heating power input has maxima in the neighborhood of 1 watt $/ \mathrm{cm}^{3}$, with total power input during the quasisteady phase about one megawatt.

The great complexity of the tungsten spectra in its first 40-45 states of ionization precludes the possibility of emission of very prominent lines that could be readily used for quantitative analysis of the tungsten concentration in the usual manner. Nevertheless, recent observations in the ORMAK device [2], laser-produced plasmas [3,4], a theoretical study of the expected spectra [5], and extrapolations from isoelectronic sequences [6] indicate that during the entire stripping of the $n=4$ shell groups of fairly strong lines should appear in the neighborhood of 50-60 \&: If the emission characteristics of such groups or bands of radiation become sufficiently well understood it may be possible to use the entire bands for the study of the behavior of tungsten or other very heavy elements in hot plasmas, or at least for the quantitative measurements of radiative energy losses by these elements.

Figure 1 shows samples of the radiation bands ascribed to tungsten ions, in two different types of discharges (characlerized by the radial temperature profiles shown in the insel), of the PLT tokamak. These spectra were obtained on a shot-to-shot scan, with a photoelectric detector in a grazing incidence $\left(85^{\circ}\right)$ spectrometer, instrumental bandwidth $1.25 \AA$. A spectrometer was calibrated 
for absolute intensity measurements at $40 \AA$ and $88 \AA$ (branching ratios of $\mathrm{C} V$ and Ne VIII lines, respectively), with interpolations and extrapolations at other wavelengths. Scattered light from the grating (important at wavelength positions below $40 \AA$ ) has been separately measured and subtracted in the figure.

The radial profiles of electron temperature and density, and the volume emissivity of the peak at $51 \AA$ of the tungsten radiation in similar two discharges, are shown in Fig. 2 . In both cases the electron densities and temperatures were nearly constant (within $\approx 10 \%$ ) for at least $50 \mathrm{msec}$ before and after the time of the measurement.

The electron temperature range, about $400-1600 \mathrm{eV}$, where the tungsten bands originate gives an indication of the range of ionization potentials of the tungsten ions emitting this radiation. These states should be near but probably slightly below coronal equilibrium values. According to a recent calculation [7] of the expected ionization states, the emission must span the range from about $\mathrm{W} X \mathrm{x}$ to W XXXV, i.e., throughout the stripping of the $4 \mathrm{f}$ and part of the $4 \mathrm{~d}$ subshells. The observed radiation may therefore be ascribed to transitions of the type $4 d^{r} 4 f^{s-1}-4 d^{r-l} 4 f^{s}$, and the remarkably small variation of the spectrum with temperature (Fig. 1) may be taken as evidence that the $4 d$ subshell (ionization potentials $1200-1600 \mathrm{eV}$ ) is indeed 
not entirely stripped by $\mathrm{T}_{\mathrm{e}}=1600 \mathrm{eV}$. Yet, it is evident from Fig. 2 (b) that a large fraction of the tungsten radiation arises from the same or even slightly narrower region as Fe XXIII (ionization potential $1950 \mathrm{eV}$ ) observed in the same discharge. The coexistence of ions with such disparate ionization:potentials must be due to an efficient recombination mechanism of the $\mathrm{W}$ ions.

The explicit density dependence of the radiation is probably $\propto \mathrm{n}^{2}(\mathrm{r})$ (i.e., corresponding to a radially constant fraction of tungsten concentration). The radial light distribution on Fig. 2 (b) then indicates in the $51 \AA$ band of radiation efficiency increasing with temperature up to at least $1500 \mathrm{eV}$. Since the excitation rate coefficient at about 2-6 times threshold energy should be nearly independent of $\mathrm{T}_{e}$, the radiation efficiency must be increasing with the ionization state. Radial scans off the spectral peak, e.g. at $58 \AA$ indicate somewhat less radially peaked profiles, in qualitative agreement with the narrowing of the spectral distributions at higher Te (Fig. I). The $33 \AA$ band may also be slight.ly broader radially than the $51 \AA$ peak (hence pertaining to lower temperature). In the case of the hollow discharge (Fig. 2(a)), the relatively high emissivity near the center is probably due Lu devlations from coronal equilibrium caused by radial 
drift of the ions (estimated velocities $(1-2) \times 10^{3} \mathrm{~cm} / \mathrm{sec}$ ), i.e., the states of ionization are somewhat below equilibrium outside $\mathrm{T}_{\mathrm{e}}$ maximum, and above inside.

An emission of $10^{14}$ photons $/ \mathrm{cm}^{3}-\mathrm{sec}-\AA$ at the $51 \AA$ maximum corresponds to an emissive power for the three bands of about $50-60 \mathrm{~mW} / \mathrm{cm}^{3}$. Thus the total radiated power is comparable to the power input densities. Comparison of the radiation magnitudes in Fig. $2(a)$ and (b) at $r \approx 15-20 \mathrm{~cm}$ suggests a tungsten concentration some 3-4 times higher in the hollow discharge case. (The absolute concentrations are estimated from probable excitation rates to be of the order $\left.10^{10}-10^{11} \mathrm{~cm}^{-3}\right)$. Indeed it appears that the high tungsten concentration is a necessary condition for developing the hollow temperature profile by providing the necessary heat sink in the center of the discharge.

The authors are indebted to the PLT group at Princeton Plasma Physics Laboratory for uperaling the light eourse, and for measurement of the electron temperatures and densities: This work. was supported by U. S. ERDA Contract $\mathrm{EY}-76-\mathrm{C}-02-3073$. 
REFERENCES

[1] D. Grove, et al., Plasma Physics and Controlled Nuclear Fusion Research, IAEA, Vienna 1977, Vol. I, p. 21.

[2] R. C. Isler, R. V. Neidigh, and R. D. Cowan, Phys. Letters, 1977, to be published.

[3] P. G. Burkhalter, D. J. Nagel and R. D. Cowan, NRL Report 3444,1977 , unpublished.

[4] R. J. Dewhurst, M. A. Khan and G. J. Pert, J. Phys. B $\underline{3}$, (1975) 2301.

[5] R. D. Cowan, LASL Report LA-6679-MS, 1977, unpublished.

[6] J. Sugar, J. Opt. Soc. Am., 1977, to be published.

[7] D. E. Post, R. V. Jensen, W. H. Grasberger, C. B. Tarter and W. A. Lokke, PPPL-1134 (1977), to be published in Nuclear Fusion. 


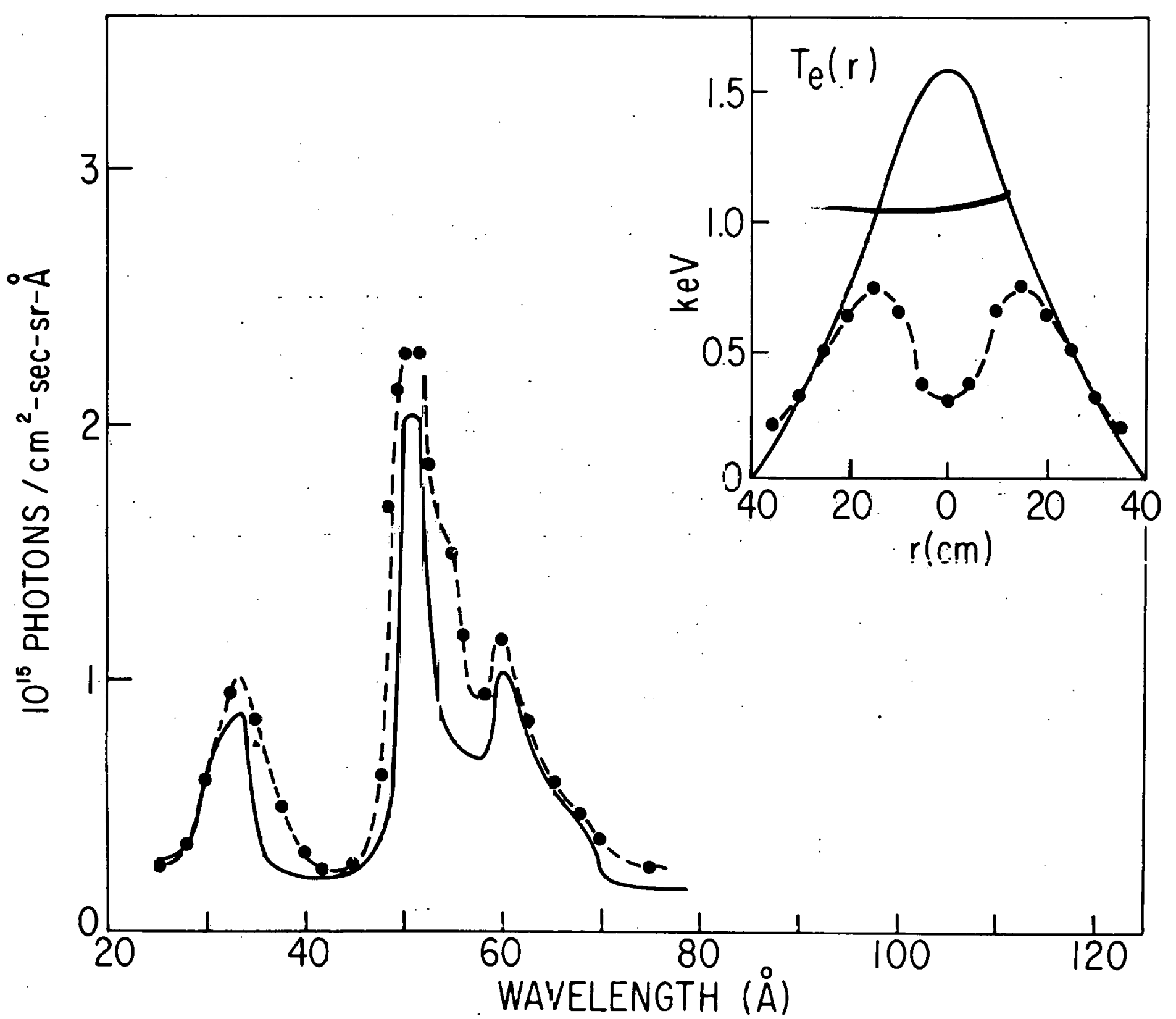

773673

Fig. 1. Observed tungsten spectra pertaining to the two electron temperature profiles shown in the inset. 


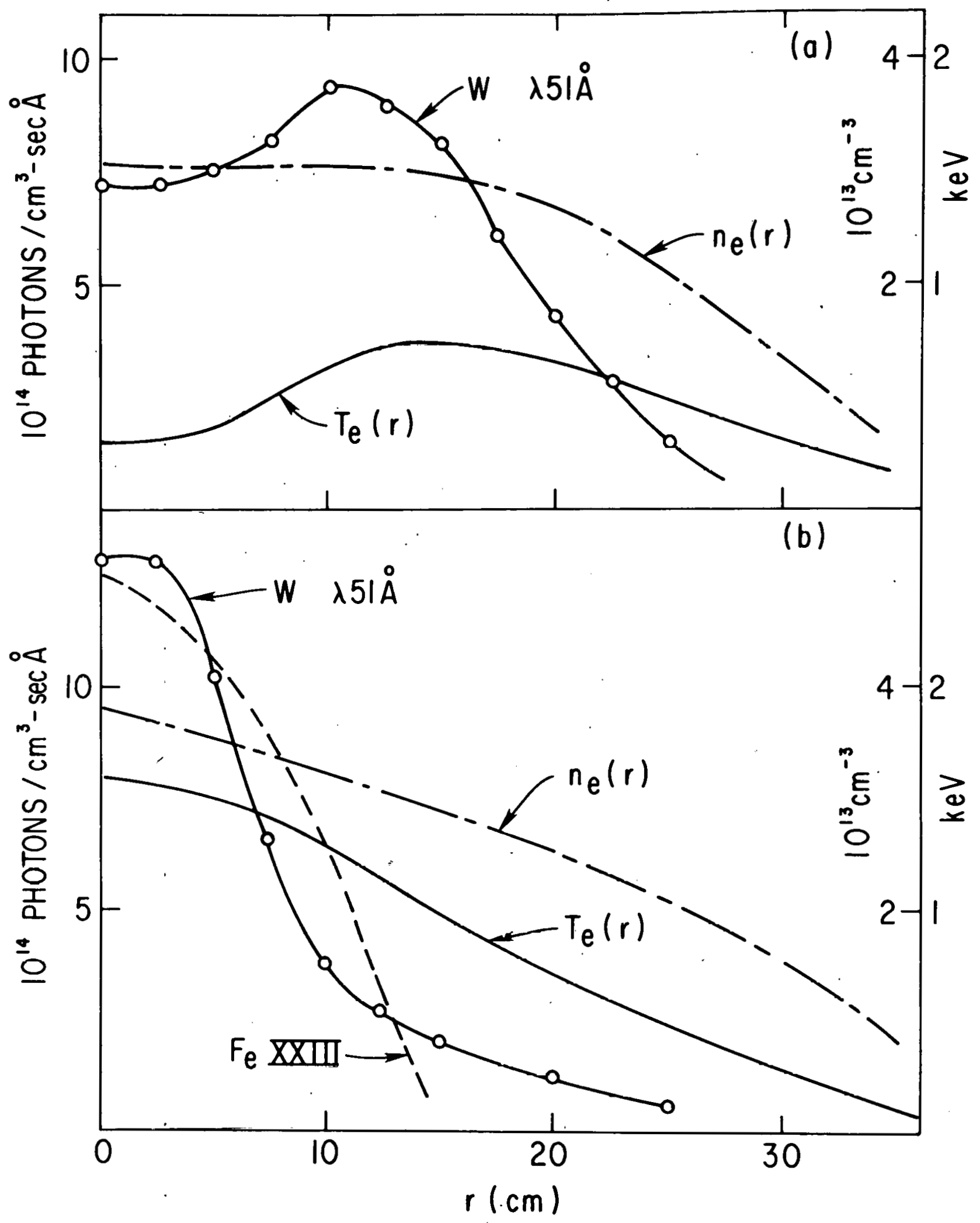

773699

Fig. 2. Radial distributions of electron density and temperature (right scales) and the $51 \AA$ band peak intensity (left scale ( during the quasisteady phase of (a) hollow and (b) peaked-temperature discharges. Also shown is the distribution of $\mathrm{Fe}$ XXIII ion in the latter discharge. 